\title{
Bound of aspect ratio of base- isolated buildings considering nonlinear tensile behavior of rubber bearing
}

\section{AUTHOR(S):}

Hino, J.; Yoshitomi, S.; Tsuji, M.; Takewaki, Izuru

\section{CITATION:}

Hino, J....[et al]. Bound of aspect ratio of base-isolated buildings considering nonlinear tensile behavior of rubber bearing. Structural Engineering and Mechanics 2008, 30(3): 351368

\section{ISSUE DATE:}

2008-10

URL:

http://hdl.handle.net/2433/89640

\section{RIGHT:}

(C) 2009 Techno Press; This is not the published version. Please cite only the published version.; この論文は出版社版でありません。引用の 際には出版社版をご確認ご利用ください。 


\title{
Bound of aspect ratio of base-isolated buildings considering nonlinear tensile behavior of rubber bearing
}

\author{
J. Hino, S. Yoshitomi, M. Tsuji, I. Takewaki ${ }^{*}$ \\ Dept. of Urban \& Environmental Eng., Graduate School of Eng., Kyoto University, \\ Kyotodaigaku-Katsura, Nishikyo, Kyoto 615-8540, Japan
}

\begin{abstract}
The purpose of this paper is to propose a simple analysis method of axial deformation of base-isolation rubber bearings in a building subjected to earthquake loading and present its applicability to the analysis of the bound of the aspect ratio of base-isolated buildings. The base shear coefficient is introduced as a key parameter for the bound analysis. The bound of the aspect ratio of base-isolated buildings is analyzed based on the relationship of the following four quantities; (i) ultimate state of the tensile stress of rubber bearings based on a proposed simple recursive analysis for seismic loading, (ii) ultimate state of drift of the base-isolation story for seismic loading, (iii) ultimate state of the axial compressive stress of rubber bearings under dead loads, (iv) prediction of the overturning moment at the base for seismic loading. In particular, a new recursive analysis method of axial deformation of rubber bearings is presented taking into account the nonlinear tensile behavior of rubber bearings and it is shown that the relaxation of the constraint on the ultimate state of the tensile stress of rubber bearings increases the limiting aspect ratio.
\end{abstract}

Key words: Base-isolation, Bound of building aspect ratio, Analysis of axial deformation of rubber bearing, Recursive analysis, Nonlinear uplift, Base shear coefficient

\footnotetext{
* Corresponding author. Tel.: +81-75-383-3294, Fax: +81-75-383-3297,

E-mail: takewaki@archi.kyoto-u.ac.jp
} 


\section{Introduction}

It is usually recognized (e.g., see Kelly 1999; Naeim and Kelly, 1999;Jangid 1995; Jangid and Datta 1994; Jangid and Banerji 1998; Morales 2003; Kobori 2004; Takewaki 2004, 2005, 2008) that base-isolation (BI) systems are very useful in reducing the acceleration and displacement responses relative to base of buildings caused by earthquakes. BI systems were introduced in many buildings and facilities after the Northridge earthquake (1994) and Hyogo-ken Nanbu earthquake (1995). It is believed that BI systems are effective only for ground motions without long-period components. In fact, most of the ground motions recorded in the USA include high-frequency components in general, and long-period ground motions (Irikura et al., 2004; Kamae et al., 2004) have never been discussed except in a few cases, e.g. Landers in 1992 and Northridge in 1995 (Heaton et al., 1995; Hall et al., 1995; Jangid and Kelly, 1999). Even in these cases, the period range of the long-period wave components, so-called pulse waves, is rather short (2-3s) compared to those (5-10s) discussed in Japan.

BI systems are effective for low-rise stiff buildings and most of BI systems have been installed in those buildings (Kobori 2004). However, not a few tall base-isolated buildings are being planned and constructed in Japan (Ariga et al. 2006). In this situation, it may be meaningful to discuss the bound of aspect ratio of tall base-isolated buildings and clarify the characteristics of such buildings ( $\mathrm{Li}$ and $\mathrm{Wu} 2006$ ).

The purpose of this paper is to propose a simple analysis method of axial deformation of base-isolation rubber bearings in a building subjected to earthquake loading and present its applicability to the analysis of the bound of the aspect ratio of base-isolated buildings. The base shear coefficient is introduced as a key parameter for the bound analysis. The bound of the aspect ratio of base-isolated buildings is analyzed based on the relationship of the following four quantities; (i) ultimate state of the tensile stress of rubber bearings based on a proposed recursive analysis for seismic loading, (ii) ultimate state of drift of the base-isolation story for seismic loading, (iii) ultimate state of the axial compressive stress of rubber bearings under dead loads, (iv) prediction of overturning moment at the base for seismic loading. A new simple recursive analysis method of axial deformation of rubber bearings is presented 
taking into account the nonlinear tensile behavior of rubber bearings and it is shown that the relaxation of the constraint on ultimate state of the tensile stress of rubber bearings increases the limiting aspect ratio.

\section{Definition of bound of aspect ratio}

The definition of bound of aspect ratio is shown in Fig.1. The plan of the building is given and the size and location of rubber bearings are also prescribed. Then the ratio of the building height to the building width is defined as the aspect ratio and its limiting value is found. The constraints on the following three design conditions are considered here.

(i) The design condition on the compressive stress of rubber bearings under dead loads

(ii) The design condition on the tensile stress of rubber bearings under dead loads and seismic disturbance (the limiting value of tensile stress is $1 \mathrm{~N} / \mathrm{mm}^{2}$ )

(iii) The design condition on the shear deformation of rubber bearings under seismic disturbance

The constraint on axial compressive stress of rubber bearings under dead loads and seismic disturbance is assumed now to be satisfied. In fact, the control of the axial stress of rubber bearings under dead loads and the tensile stress of rubber bearings under seismic loading enables one to satisfy that constraint in a direct manner. If desired, this constraint can be added without difficulty.

The most direct method to obtain the bound of aspect ratio is to change the building height sequentially and evaluate the above-mentioned design conditions. When one of the design constraints is violated for the first time, that aspect ratio becomes the limiting value (bound). While this procedure is direct, the check of the design condition (ii) is elaborate. For this reason, the base shear coefficient is used as a key parameter in this paper and a simple analysis method is proposed of axial deformation of base-isolation rubber bearings. An evaluation method is also proposed simultaneously of the base shear coefficient under a design response spectrum. Its applicability to the analysis of the bound of the aspect ratio of base-isolated buildings is discussed in detail. 


\section{Seismic response evaluation method in terms of base shear coefficient}

Consider an $N$-story shear building model, as shown in Fig.2, supported by a base-isolation system. The base-isolation system consists of a linear stiffness element (natural rubber bearing) and a linear viscous damping element (oil damper), as shown in Fig.3, in the horizontal direction. On the other hand, the axial restoring-force characteristics of the rubber bearings of the base-isolation system have different stiffnesses in the compressive and tensile stress regions. The stiffness in the tensile stress region is one-tenth of that in the compressive region.

Let $m_{i}, k_{i}, c_{i}, h_{i}$ denote the mass, story stiffness, story damping coefficient and the story height of the $i$-th story, respectively. The floor mass just above the base-isolation story, the stiffness and damping coefficient of the base-isolation story and the story height of the base-isolation story are denoted by $m_{0}, k_{0}, c_{0}, h_{0}$, respectively (see Fig.3). Let $x_{0}$ and $x_{i}$ denote the horizontal displacement of the floor just above the base-isolation story and that of the floor in the (i+1)-th story. Then the set of $x_{0}$ and $x_{1}, \cdots, x_{N}$ is denoted by $\{x\}$.

Let $[M],[C],[K],\{1\}$ denote the mass, damping and stiffness matrices and the vector consisting of $N$ unities, respectively. In this paper, the lowest mode is used to transform the MDOF model to an equivalent reduced SDOF model. The equations of motion for this model may be expressed by

$$
[M]\{\ddot{x}\}+[C]\{\dot{x}\}+[K]\{x\}=-[M]\{1\} \ddot{x}_{g}
$$

\subsection{Transformation of MDOF model to SDOF model and the aspect ratio-base shear coefficient relation determined from the design condition on tensile stress of rubber bearings}

If the building deformation can be described approximately by the lowest-mode only, the base shear and overturning moment at the base can be expressed by

$$
Q=M_{1}\left(\ddot{q}_{0}^{(1)}+\ddot{x}_{g}\right)
$$




$$
M_{o v}=M_{1} H_{1}\left(\ddot{q}_{0}^{(1)}+\ddot{x}_{g}\right)
$$

where $M_{1}$ and $H_{1}$ are the equivalent mass and the equivalent height of the equivalent SDOF model described by $M_{1}=\beta_{1} \sum_{i=0}^{N}\left(m_{i} u_{i}^{(1)}\right), H_{1}=\beta_{1} \sum_{i=0}^{N}\left(m_{i} h_{i} u_{i}^{(1)}\right) / M_{1} \cdot \quad q_{0}^{(1)}$ is the lowest-mode normal coordinate and $u_{i}^{(1)}$ and $\beta_{1}$ are the lowest-mode horizontal displacement and the participation factor of the lowest mode.

From Eqs.(2) and (3), the relation $M_{o v}=Q H_{1}$ holds. The aspect ratio-base shear coefficient relation determined from the design condition on tensile stress of rubber bearings can then be obtained from this relation and the recursive analysis shown in Section 4.

\subsection{Horizontal deformation in the base-isolation story}

If the base shear coefficient $C_{B}$ is given, then the base shear can be expressed by

$$
Q=\left(\sum_{i=0}^{N} m_{i}\right) C_{B} g
$$

Eq.(2) can also be expressed as

$$
Q=\beta_{1}\left(\sum_{i=0}^{N} m_{i} u_{i}^{(1)}\right)\left(\ddot{q}_{0}^{(1)}+\ddot{x}_{g}\right)
$$

Eqs.(4) and (5) provide

$$
\ddot{q}_{0}^{(1)}+\ddot{x}_{g}=C_{B} g\left(\sum_{i=0}^{N} m_{i}\right) /\left(\beta_{1} \sum_{i=0}^{N} m_{i} u_{i}^{(1)}\right)
$$

Let $d$ denote the horizontal deformation in the base-isolation story. By keeping $\ddot{q}_{0}^{(1)}+\ddot{x}_{g}=\omega_{1}^{2} q_{0}^{(1)}, \quad d=\beta_{1} u_{0}^{(1)} q_{0}^{(1)}$ in mind, $d$ can be expressed as

$$
d=u_{0}^{(1)} C_{B} g\left(\sum_{i=0}^{N} m_{i}\right) /\left(\omega_{1}^{2} \sum_{i=0}^{N} m_{i} u_{i}^{(1)}\right)
$$

where $g$ and $\omega_{1}$ denote the gravitational acceleration and the fundamental natural circular 
frequency of the model. Eq.(7) provides the aspect ratio-base shear coefficient relation determined from the design condition on horizontal deformation in the base-isolation story.

If desired, the P- $\Delta$ effect can be taken into account by decreasing the base-isolation story stiffness.

\subsection{Aspect ratio-base shear coefficient relation determined from the design condition on compressive stress under dead loads}

This aspect ratio-base shear coefficient relation does not depend on the base shear coefficient and can be evaluated directly from the total weight of the building and foundation and the total cross-sectional area of rubber bearings.

\subsection{Aspect ratio-response base shear coefficient relation}

The building is designed based on the relation $T_{1}=0.02 \mathrm{H}$ of the fundamental natural period $T_{1}$ (s) with the building height $H(\mathrm{~m})$. The fundamental mode of the building with a fixed base is assumed to be a straight line and the story stiffnesses are determined via an inverse problem formulation (Nakamura and Yamane 1986). Two models are used as the models for response spectrum method in order to evaluate the response base shear coefficient; one is a 2DOF model consisting of the SDOF building and the SDOF base-isolation system, the other is an SDOF model transforming the total system into a single-degree-of-freedom system.

The schematic diagram of the procedure for evaluating the response base shear coefficient with respect to the aspect ratio in terms of SDOF and 2DOF models is shown in Fig.4. The detailed explanation will be provided in Section 5. From this procedure, the aspect ratio-response base shear coefficient relation can be derived.

\section{Recursive analysis of rubber bearing axial deformation allowing the nonlinear tensile} behavior

It is usually believed that the nonlinear time-history response analysis is inevitable in order to evaluate the nonlinear response of the base-isolation system under seismic 
disturbances. However, it may be possible to develop a simple method of analysis of axial deformation of rubber bearings which allows the nonlinear tensile behavior of rubber bearings. The nonlinear axial force-deformation relation of rubber bearings is shown in Fig.5. It is assumed that a special mechanism (for example, a flat-type spring surrounded by a round wall) is incorporated in the base-isolation system and the performance of horizontal resistance of rubber bearings remains unchanged even after the stress of a rubber bearing goes into a tensile region. In other words, the horizontal resistance of rubber bearings is guaranteed by the round wall even if the stress of a rubber bearing goes into a tensile region. This mechanism has been invented in Japan for base-isolation.

Consider a simple model, as shown in Fig.6, consisting of the axial springs representing rubber bearings and the shear springs modeling connecting beams. Let $n$ and $2 l$ denote the number of columns (and rubber bearings) in a frame of interest and the distance between the outer columns (or outer rubber bearings). It is assumed that $n$ is an odd number. Let $k_{0}^{\prime}(i)$ and $k^{\prime}$ denote the axial stiffness of $i$-th rubber bearing from the left end (called $i$-th rubber bearing hereafter) and the common shear stiffness of the beam, respectively. When the left-end rubber bearing goes into a tensile range, $k_{0}^{\prime}(1)$ decreases and the small tensile stiffness is employed in that case. This model is subjected to column axial forces $\left\{f_{i}\right\}$.

Let $\Delta y_{i}$ denote the shear deformation of the connecting beam between the $i$-th column and $(i+1)$-th column. The total axial deformation $y_{i}$ of the $i$-th rubber bearing consists of the component $\sum_{j=1}^{i-1} \Delta y_{j}$ due to shear deformation of the connecting beam and that $y(i)=y_{i}-\sum_{j=1}^{i-1} \Delta y_{j}$ excluding the component of shear deformation of the connecting beam as shown in Fig.7. The displacement component $y(i)=y_{i}-\sum_{j=1}^{i-1} \Delta y_{j}$ results from the rigid motion of the beam. The total axial deformation $y_{i}$ of the $i$-th rubber bearing can be expressed by

$$
\begin{array}{ll}
y_{i}=y+\frac{2(i-1)}{n^{\prime}-1} l \theta+\sum_{j=1}^{i-1} \Delta y_{j} & (i \neq 1) \\
y_{i}=y & (i=1)
\end{array}
$$

The overturning moment $M_{o v}$ at the base (the top level of the base-isolation system) 
has been evaluated in Section 3.4. Given the overturning moment, the column axial forces $\left\{f_{i}\right\}$ can be related to the overturning moment.

$$
\frac{2 l}{n-1} \sum_{i=1}^{n} \frac{(n+1-2 i)}{2} f_{i}=M_{o v}
$$

If the distribution of $\left\{f_{i}\right\}$ is given, then the magnitude of $\left\{f_{i}\right\}$ can be determined from Eq.(9).

The equilibrium equation in the vertical direction of the node above every rubber bearing may be described in a recursive manner by

$$
\begin{gathered}
k_{0}^{\prime}(1) y-k^{\prime} \Delta y_{1}=f_{1} \\
\vdots \\
k_{0}^{\prime}(i)\left(y+\frac{2(i-1)}{n^{\prime}-1} l \theta+\sum_{j=1}^{i-1} \Delta y_{j}\right)+k^{\prime} \Delta y_{i-1}-k^{\prime} \Delta y_{i}=f_{i} \\
\vdots \\
k_{0}^{\prime}(n)\left(y+\frac{2}{n-1} l \theta+\sum_{j=1}^{n-1} \Delta y_{j}\right)+k^{\prime} \Delta y_{n-1}=f_{n}
\end{gathered}
$$

In addition, the equation of moment equilibrium around the top of the first rubber bearing can be expressed as

$$
\sum_{i=1}^{n} \frac{2(i-1)}{n-1} l k_{0}^{\prime}(i) y_{i}=\sum_{i=2}^{n} \frac{2(i-1)}{n-1} l k_{0}^{\prime}(i)\left\{y+\frac{2(i-1)}{n-1} l \theta+\sum_{j=1}^{i-1} \Delta y_{j}\right\}=\sum_{i=1}^{n} \frac{2(i-1)}{n-1} l f_{i}
$$

The set of equilibrium equations (10) and (11) may be described alternatively as

$$
\begin{gathered}
k_{0}^{\prime}(1) y-k^{\prime} \Delta y_{1}=f_{1} \\
\frac{2}{n^{\prime}-1} k_{0}^{\prime}(2) l \theta+k_{0}^{\prime}(2) y-\left\{k_{0}^{\prime}(2)+k^{\prime}\right\} \Delta y_{1}-k^{\prime} \Delta y_{2}=f_{2} \\
\vdots \\
\frac{2(i-1)}{n^{\prime}-1} k_{0}^{\prime}(i) l \theta+k_{0}^{\prime}(i) y+\sum_{j=1}^{i-2} k_{0}^{\prime}(i) \Delta y_{j}+\left\{k_{0}^{\prime}(i)+k^{\prime}\right\} \Delta y_{i-1}-k^{\prime} \Delta y_{i}=f_{i} \\
\vdots \\
2 k_{0}^{\prime}(n) l \theta+k_{0}^{\prime}(n) y+\sum_{j=1}^{n-2} k_{0}^{\prime}(n) \Delta y_{j}+\left\{k_{0}^{\prime}(n)+k^{\prime}\right\} \Delta y_{n-1}=f_{n}
\end{gathered}
$$




$$
\sum_{i=1}^{n}\left\{\frac{2(i-1)}{n-1}\right\}^{2} k_{0}^{\prime}(i) l \theta+\sum_{i=1}^{n} \frac{2(i-1)}{n-1} k_{0}^{\prime}(i) y+\sum_{j=2}^{n} \sum_{i=j}^{n} \frac{2(i-1)}{n-1} k_{0}^{\prime}(i) \Delta y_{j-1}=\sum_{i=1}^{n} \frac{2(i-1)}{n-1} f_{i}
$$

The set of equilibrium equations (12) and (13) may be expressed compactly as

$$
\left.\begin{array}{cccccc}
0 & k_{0}^{\prime}(1) & -k^{\prime} & & \cdots & 0 \\
\vdots & \vdots & k_{0}^{\prime}(2)+k^{\prime} & -k^{\prime} & & \\
\frac{2(i-1)}{n-1} k_{0}^{\prime}(i) l & k_{0}^{\prime}(i) & \vdots & \ddots & \ddots & \vdots \\
\vdots & \vdots & k_{0}^{\prime}(n-1) & k_{0}^{\prime}(n-1) & k_{0}^{\prime}(n-1)+k^{\prime} & -k^{\prime} \\
2 k_{0}^{\prime}(n) l & k_{0}^{\prime}(n) & k_{0}^{\prime}(n) & \cdots & k_{0}^{\prime}(n) & k_{0}^{\prime}(n)+k^{\prime} \\
\sum_{i=1}^{n}\left\{\frac{2(i-1)}{n-1}\right\}^{2} k_{0}^{\prime}(i) l & \sum_{i=1}^{n} \frac{2(i-1)}{n-1} k_{0}^{\prime}(i) & \sum_{i=2}^{n} \frac{2(i-1)}{n-1} k_{0}^{\prime}(i) & \cdots & \sum_{i=n-1}^{n} \frac{2(i-1)}{n-1} k_{0}^{\prime}(i) & 2 k_{0}^{\prime}(n)
\end{array}\right]\left\{\begin{array}{c}
\theta \\
y \\
\Delta y_{1} \\
\Delta y_{2} \\
\vdots \\
\Delta y_{n-1}
\end{array}\right\}
$$

Substitution of Eq.(12) into Eq.(13) and elimination of $\left\{f_{i}\right\}$ lead to

$$
\Delta y_{1}+\Delta y_{2}+\cdots+\Delta y_{n-1}=0
$$

Incorporation of Eq.(15) into Eq.(14) provides

$$
\left[\begin{array}{cccccc}
0 & k_{0}^{\prime}(1) & -k^{\prime} & & \cdots & 0 \\
\vdots & \vdots & k_{0}^{\prime}(2)+k^{\prime} & -k^{\prime} & & \\
\frac{2(i-1)}{n-1} k_{0}^{\prime}(i) l & k_{0}^{\prime}(i) & \vdots & \ddots & \ddots & \vdots \\
\vdots & \vdots & k_{0}^{\prime}(n-1) & k_{0}^{\prime}(n-1) & k_{0}^{\prime}(n-1)+k^{\prime} & -k^{\prime} \\
2 k_{0}^{\prime}(n) l & k_{0}^{\prime}(n) & k_{0}^{\prime}(n) & \cdots & k_{0}^{\prime}(n) & k_{0}^{\prime}(n)+k^{\prime} \\
0 & 0 & 1 & 1 & \cdots &
\end{array}\right]\left\{\begin{array}{c}
\theta \\
y \\
\Delta y_{1} \\
\Delta y_{2} \\
\vdots \\
\Delta y_{n-1}
\end{array}\right\}
$$

In the first cycle, all the stiffnesses $k_{0}^{\prime}(1), \cdots, k_{0}^{\prime}(n)$ are assumed to be the stiffnesses in compression. The axial stress of the left-end rubber bearing has a one-to-one 
correspondence with $y$. Therefore, if the axial tensile strength of the rubber bearing is given, the corresponding displacement $y$ can be obtained. For the given aspect ratio and $y$, the corresponding base shear coefficient, related with $\left\{f_{i}\right\}$ in terms of the aspect ratio, and the other unknowns $\theta, \Delta y_{1}, \ldots, \Delta y_{n-1}$ can be obtained. In this way, the aspect ratio-base shear coefficient relation can be derived. It should be noted that, if the axial deformation of the left-end rubber bearing is negative (in elongation), then the stiffness $k_{0}^{\prime}(1)$ has to be changed to the stiffness in tension. This procedure has to be repeated until all the combinations of the stiffness and the deformation are compatible.

\section{Seismic response evaluation method}

In this paper, a reduced SDOF model and another 2DOF model, as shown in Fig.8, are used in order to evaluate the response base shear coefficient and response overturning moment at the base under seismic loading.

\subsection{Building model}

The plan of an $N$-story shear building model supported by a base-isolation system is shown in Fig.9 and the building parameters are explained in Table 1. The vertical and horizontal stiffness of the natural rubber bearing of height $356.6 \mathrm{~mm}$ and diameter $800 \mathrm{~mm}$ are $2.93 \times 10^{9} \mathrm{~N} / \mathrm{m}$ and $1.22 \times 10^{6} \mathrm{~N} / \mathrm{m}$, respectively. It is assumed that the horizontal stiffness does not change, but the vertical stiffness becomes $1 / 10$ of the original in the tensile stress range. The allowable compressive stress of rubber bearings under dead loads is $14.7 \mathrm{~N} / \mathrm{mm}^{2}$ and the allowable horizontal deformation of rubber bearings is $0.48 \mathrm{~m}$. The fundamental natural period of the building with a fixed base is specified as $0.02 \times H$ (s) where $H$ is the height in meter of the building. The lowest mode of the building with a fixed base is assumed to be a straight line and the story stiffnesses of the building are computed from the inverse design method (Nakamura and Yamane 1986). The shear spring stiffness of the standard foundation reinforced-concrete beam of $1000 \mathrm{~mm} \times 1000 \mathrm{~mm}$ is $1.95 \times 10^{8} \mathrm{~N} / \mathrm{m}$ and three other cases, $1.95 \times 10^{6} \mathrm{~N} / \mathrm{m} ; 1.95 \times 10^{9} \mathrm{~N} / \mathrm{m} ; 1.95 \times 10^{11} \mathrm{~N} / \mathrm{m}$, are also treated.

The damping matrix of the building is assumed to be proportional to the stiffness matrix 
and the lowest-mode damping ratio of the building with a fixed base is given by 0.05 . The damping coefficient of the base-isolation system is prescribed by giving the damping ratio as 0.1 for a rigid superstructure. The total damping ratio of the whole system is evaluated by a modal approximation method (Thomson et al. 1974).

\subsection{Evaluation of overturning moment and base shear coefficient}

\subsubsection{Evaluation by SDOF model}

Let $S_{A 1}, M, H$ denote the acceleration response spectrum corresponding to the lowest mode, the equivalent mass of SDOF model and the equivalent height of the equivalent mass of SDOF model. The response overturning moment and response base shear coefficient can be expressed by

$$
\begin{aligned}
& M_{o v}=M H S_{A 1} \\
& C_{B}=S_{A 1} / g
\end{aligned}
$$

\subsubsection{Evaluation by 2DOF model}

Let $S_{A 1}, S_{A 2}$ and $\beta_{1}, \beta_{2}$ denote the acceleration response spectra and modal participation factors corresponding to the lowest and second modes, respectively. The lowest and second-mode component overturning moments $M_{o v}^{(1)}, M_{o v}^{(2)}$ and the lowest and second-mode component base shear coefficients $C_{B}^{(1)}, C_{B}^{(2)}$ can be expressed by

$$
\begin{aligned}
& M_{o v}^{(i)}=\beta_{i} S_{A i}\left(m_{0} u_{0}^{(i)} h_{0}+M_{1} u_{1}^{(i)} H_{1}\right) \\
& C_{B}^{(i)}=\frac{\beta_{i} S_{A i}\left(m_{0} u_{0}^{(i)}+M_{1} u_{1}^{(i)}\right)}{\left(m_{0}+M_{1}\right) g}
\end{aligned}
$$

Then the response overturning moment and response base shear coefficient can be expressed by

$$
M_{o v}=\sqrt{\left(M_{o v}^{(1)}\right)^{2}+\left(M_{o v}^{(2)}\right)^{2}}
$$




$$
C_{B}=\sqrt{\left(C_{B}^{(1)}\right)^{2}+\left(C_{B}^{(2)}\right)^{2}}
$$

In order to show the validity of the present response evaluation method, another model as a full MDOF model has been used. A standard foundation reinforced-concrete beam of $1000 \mathrm{~mm} \times 1000 \mathrm{~mm}$ is used. Fig.10 shows the response overturning moment at the base with respect to the aspect ratio and the response base shear coefficient with respect to the aspect ratio. It can be observed that the SDOF model is an appropriate model for response evaluation of the base shear coefficient and the overturning moment at the base.

Fig.11 shows the comparison between the horizontal displacement of the SDOF model and the horizontal displacement at the same height level due to the rocking of the connecting beam of the proposed simplified model. By investigating the contribution of the horizontal displacement due to the rocking of the base-isolation floor, the validity of the proposed model as a shear-type structure can be shown. It can be understood from Fig.11 that, if the aspect ratio is smaller than 6 approximately, the contribution of the horizontal displacement due to the rocking of the base-isolation floor becomes smaller than $5 \%$ and the SDOF model ignoring the rocking displacement can be used as an appropriate model.

\section{Analysis of bound of aspect ratio}

The principal purpose of this section is to clarify the effect of the nonlinear tensile behavior of rubber bearings on the bound of aspect ratio. An SDOF model is used as a model for the seismic response evaluation and it is assumed that the deformation can be described approximately by the lowest-mode vibration component only. This assumption is well recognized in the structural design practice of base-isolated buildings. The acceleration response spectrum for large earthquakes used in Japan (2000) is employed and is shown in Fig.12 for damping ratio=0.05. That acceleration response spectrum (in $\mathrm{m} / \mathrm{s}^{2}$ ) for damping ratio $=0.05$ can be expressed in terms of the natural period $T$ by

$$
\begin{aligned}
& S_{A}=3.2+30 T(T<0.16 s) \\
& S_{A}=8.0(0.16 s<T<0.64 s) \\
& S_{A}=5.12 / T(0.64 s<T)
\end{aligned}
$$


The acceleration response spectrum for damping ratio $h$ is calculated by multiplying the coefficient $1.5 /(1.0+10 h)$ on the response spectrum for $h=0.05$. This response spectrum is similar to the well-known one (Newmark and Hall 1982).

As for the distribution of column axial forces for seismic loading, the axial force of the left-end column is four times that of the second column from the left. Furthermore, an anti-symmetric distribution is assumed. It should be pointed out that, when the stress in a rubber bearing goes into the tensile region, the distribution of column axial forces may change. It may be useful to discuss the effect of the redistribution of these column axial forces on the limiting aspect ratio. The result is shown in Appendix. It is concluded that the effect of the redistribution of these column axial forces on the limiting aspect ratio is negligible within a restricted range.

Fig.13 shows the relation of the aspect ratio with the base shear coefficient in the case where the design condition on the ultimate state of tensile stress of a rubber bearing is active (satisfied with equality) and the other design conditions are inactive (satisfied in inequality). Four foundation beam stiffnesses are considered. The intersection of this active relation with the aspect ratio-response base shear coefficient relation gives the limiting aspect ratio for the critical design condition. Two limit values $\left(0\right.$ and $\left.1 \mathrm{~N} / \mathrm{mm}^{2}\right)$ of tensile stress of rubber bearings were employed. It can be observed that the limit values $1 \mathrm{~N} / \mathrm{mm}^{2}$ of tensile stress of rubber bearings can increase the bound of aspect ratio remarkably. This implies that, when the stress in a rubber bearing goes into a tensile region, the redistribution of stresses in the other rubber bearings occurs and this mechanism of stress redistribution plays an important role in the increase of the bound of aspect ratio.

Fig.14 illustrates the axial stress variation of five rubber bearings with respect to the aspect ratio for two different connecting beam stiffnesses. It can be understood that, when the aspect ratio becomes larger, the stress of the left-end rubber bearing goes into the tensile region. In addition, it can also be observed that, if the connecting beam is stiff, the axial stress of the second rubber bearing from the left end is approaching to null. In other words, when the beam stiffness becomes larger in case of allowing the nonlinear tensile behavior of rubber bearings, the inner rubber bearings sustain the tensile stress and the tensile stress in 
the outer rubber bearings becomes smaller. This means that, the stiffer the beams are made, the larger the bound of aspect ratio of tall base-isolated buildings becomes.

Fig.15 shows the variation of the column axial forces under seismic loading with respect to the variation of the connecting beam. Fig.15 presents the comparison of the limiting aspect ratios between the case without the consideration of the vertical seismic loading and that with the consideration of the vertical seismic loading (axial stress corresponding to $0.3 \mathrm{~g}$ is added). It can be observed that the consideration of vertical seismic loading decreases the limiting aspect ratio.

\section{Conclusions}

The conclusions may be summarized as follows:

(1) A recursive analysis method of axial deformation of base-isolation rubber bearings under earthquake loading has been proposed by developing a simple model consisting of beam shear springs and rubber axial springs subjected to equivalent seismic column axial forces. The rubber axial springs have different stiffnesses in the compressive and tensile stress states. This method enables one to take into account approximately the nonlinear tensile behavior of rubber bearings without elaborate time-history response analysis.

(2) Once the stress of a rubber bearing goes into a tensile state, the seismic column axial forces may change. However the effect of this change on the limiting aspect ratio is expected to be small so long as the tensile stress is smaller than $1 \mathrm{~N} / \mathrm{mm}^{2}$. This guarantees the validity to use the same seismic column axial forces even for the nonlinear tensile behavior of rubber bearings.

(3) Relaxation of the design condition on ultimate state of the tensile stress of rubber bearings, i.e. from a null tensile stress to $1\left(\mathrm{~N} / \mathrm{mm}^{2}\right)$, increases the limiting aspect ratio.

(4) When the beam stiffness becomes larger in case of allowing the nonlinear tensile behavior of rubber bearings, the inner rubber bearings sustain part of the tensile stress and the tensile stress in the outer rubber bearings becomes smaller. This means that, stiffer the beams, larger the bound of aspect ratio of tall base-isolated buildings. 


\section{Acknowledgements}

Part of the present work is supported by the SECOM foundation. The authors are grateful for this support.

\section{Appendix I: Effect of redistribution of column axial forces on limiting aspect ratio}

Fig.A1 shows a possible scenario of redistribution of column axial forces resulting from the nonlinear tensile behavior of the rubber bearing at the left end. It is assumed that there is no additional vertical load and overturning moment due to this redistribution of column axial forces. In other words, the additional column axial forces denoted by dotted arrows are in self-equilibrium and have zero overturning moment. Fig.A2 presents the relation of the aspect ratio with the base shear coefficient for four redistribution cases of column axial forces. The left column axial force decreases by $0 \%, 5 \%, 10 \%$ and $15 \%$ from the original value. These values are derived from another static frame analysis under vertical and horizontal loading, shown in Fig.A3, with respect to variation of stiffness of the connecting beam. It can be observed that the effect of redistribution of column axial forces on the limiting aspect ratio is very small. 


\section{References}

Ariga T, Kanno Y, Takewaki I. (2006). "Resonant behavior of base-isolated high-rise buildings under long-period ground motions”. Journal of The Structural Design of Tall and Special Buildings, 15(3), 325-338.

Hall JH, Heaton TH, Halling MW, Wald DJ. (1995). “Near-source ground motion and its effect on flexible buildings”. Earthquake Spectra, 11, 569-605.

Heaton TH, Hall JH, Wald DJ, Halling MW. (1995). "Response of high-rise and base-isolated buildings in a hypothetical MW 7•0 blind thrust earthquake”. Science, 267, 206-211.

Irikura K, Kamae K, Kawabe H. (2004). “Importance of prediction of long-period ground motion during large earthquakes”. In Annual Conference of the Seismological Society of Japan, Poster session (in Japanese).

Jangid RS. (1995). “Optimum isolator damping for minimum acceleration response of base-isolated structures”. Australian Civil Engineering Transactions, 37, 325-331.

Jangid RS, Banerji P. (1998). "Effects of isolation damping on stochastic response of structures with non-linear base isolators”. Earthquake Spectra, 14, 95-114.

Jangid RS, Datta TK. (1994). “Non-linear response of torsionally coupled base isolated structure”. Journal of Structural Engineering, ASCE, 120, 1-22.

Jangid RS, Kelly JM. (2001). "Base isolation for near-fault motions”. Earthquake Engineering and Structural Dynamics, 30, 691-707.

Jennings PC. (1968). “Equivalent viscous damping for yielding structures”. Journal of the Engineering Mechanics Division, ASCE 94(EM1), 103-116.

Kamae K, Kawabe H, Irikura K. (2004). "Strong ground motion prediction for huge subduction earthquakes using a characterized source model and several simulation techniques”. In Proceedings of the13th WCEE, Vancouver.

Kelly JM. (1999). “The role of damping in seismic isolation”. Earthquake Engineering and Structural Dynamics, 28, 3-20.

Kobori T. (2004). Seismic-Response-Controlled Structure (New edition). Kajima Publisher: Tokyo (in Japanese).

Li H.-N. and Wu. X.-X. (2006). "Limitations of height-to-width ratio for base-isolated 
buildings under earthquake”. Journal of The Structural Design of Tall and Special Buildings, 15, 277-287.

Morales, C.A. (2003). “Transmissibility concept to control base motion in isolated structures”. Engng. Struct., 25(10), 1325-1331.

Naeim F, Kelly JM. (1999). Design of Seismic Isolated Structures. Wiley, New York.

Nakamura T, Yamane T. (1986). “Optimum design and earthquake-response constrained design for elastic shear buildings”. Earthquake Engineering and Structural Dynamics, 14, 797-815.

Newmark NM, Hall WJ. (1982). Earthquake Spectra and Design. Earthquake Engineering Research Institute, Berkeley, CA.

Takewaki I. (2004). "Frequency domain modal analysis of earthquake input energy to highly damped passive control structures”. Earthquake Engineering and Structural Dynamics, 33(5), 575-590.

Takewaki I. (2005). “Uncertain-parameter sensitivity of earthquake input energy to base-isolated structure”. Structural Engineering and Mechanics, 20(3), 347-362.

Takewaki I. (2008). “Robustness of base-isolated high-rise buildings under code-specified ground motions”. The Structural Design of Tall and Special Buildings (in press).

Thomson WT, Calkins C, Caravani P. (1974). “A numerical study of damping”. Earthquake Engineering and Structural Dynamics, 3, 97-103. 
Table 1 Building parameter

\begin{tabular}{|c|c|c|}
\hline \multicolumn{2}{|c|}{ floor area of model } & $20 \mathrm{~m} \times 5 \mathrm{~m}$ \\
\hline \multirow{2}{*}{$\begin{array}{l}\text { story } \\
\text { height }\end{array}$} & base-isolation story & $2 \mathrm{~m}$ \\
\hline & super-structure & $4 \mathrm{~m}$ \\
\hline \multirow{2}{*}{ floor mass } & base-isolation story & $2400 \mathrm{~kg} / \mathrm{m}^{2}$ \\
\hline & super-structure & $800 \mathrm{~kg} / \mathrm{m}^{2}$ \\
\hline \multicolumn{2}{|c|}{$\begin{array}{l}\text { fundamental natural period of } \\
\text { building with fixed base (s) }\end{array}$} & $0.02 H$ (H:building height in meter) \\
\hline \multirow[b]{2}{*}{ stiffness } & base-isolation story & total horizontal stiffness of rubber bearings \\
\hline & super-structure & $\begin{array}{l}\text { determined from straight-line lowest mode } \\
\text { for building with fixed base }\end{array}$ \\
\hline \multirow[b]{2}{*}{$\begin{array}{l}\text { damping } \\
\text { coefficient }\end{array}$} & base-isolation story & damping ratio 0.1 for rigid super-structure \\
\hline & super-structure & $\begin{array}{l}\text { stiffness-proportional with lowest-mode } \\
\text { damping ratio } 0.05\end{array}$ \\
\hline
\end{tabular}

\begin{tabular}{|l}
\hline aspect ratio-base shear coefficient relation \\
determined from seismic rubber tensile stress \\
- - - - aspect ratio-base shear coefficient relation \\
determined from horizontal rubber deformation \\
$\ldots . . . . . . .$. aspect ratio-base shear coefficient relation \\
determined from rubber stress under dead loads \\
-....-. \\
aspect ratio-response base shear coefficient \\
relation via response spectrum method
\end{tabular}

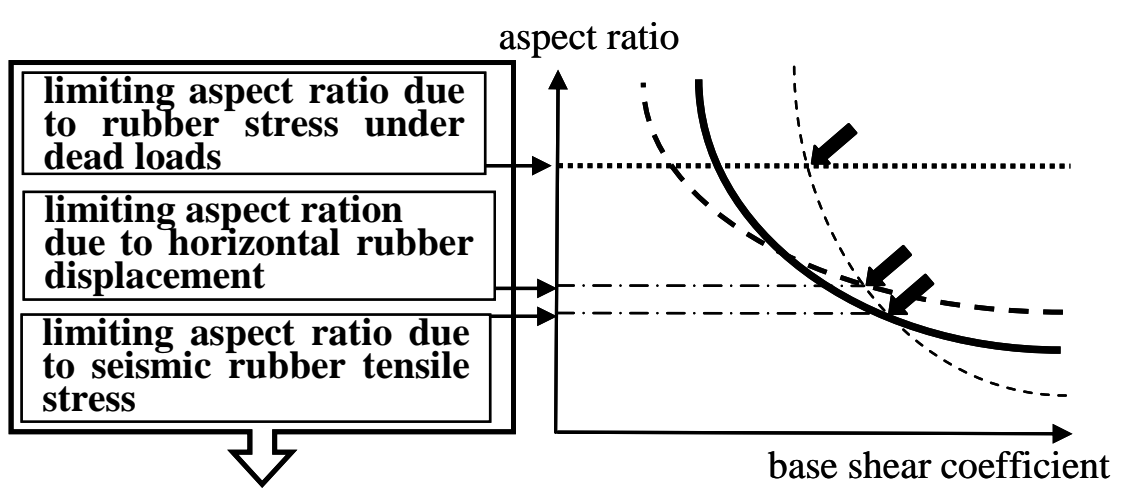

Minimum value is the limiting aspect ratio

Fig.1 Definition of bound of aspect ratio 


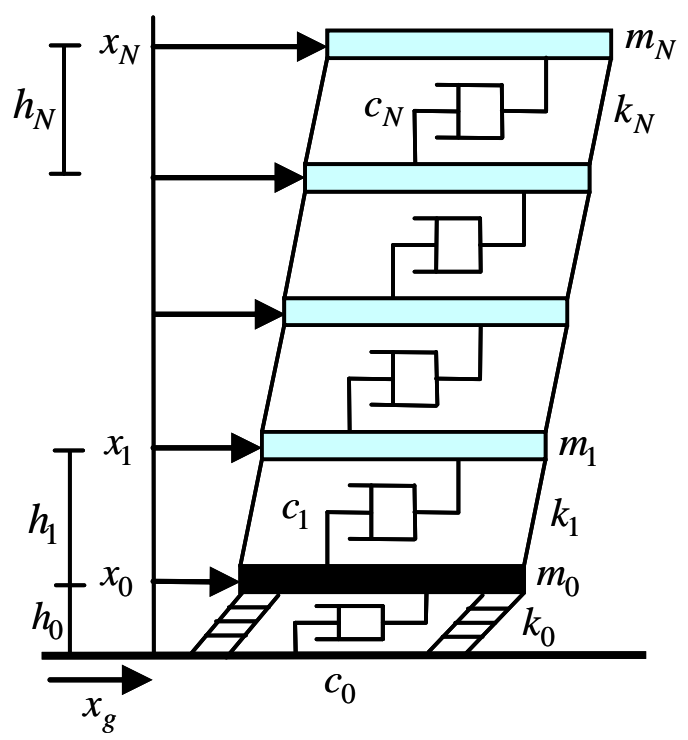

Fig.2 Shear building model supported by a base-isolation system
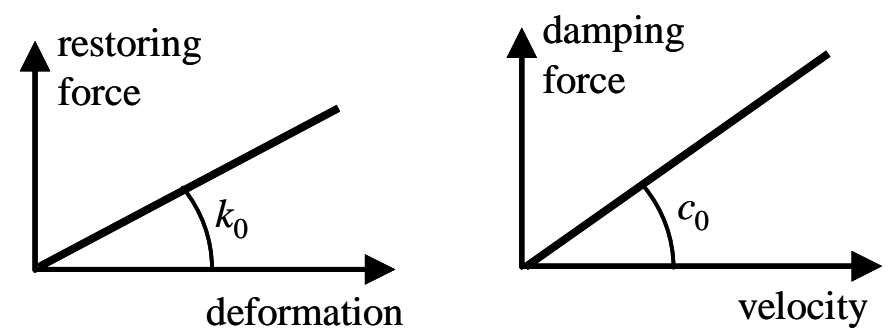

Fig.3 Shearing restoring force-deformation relation of a set of rubber bearings and damping force-velocity relation of a base-isolation damper system 

(1) specification
(2) design of building
(3) equivalent model
(4) evaluation of of aspect ratio (SDOF or 2DOF base shear coefficient

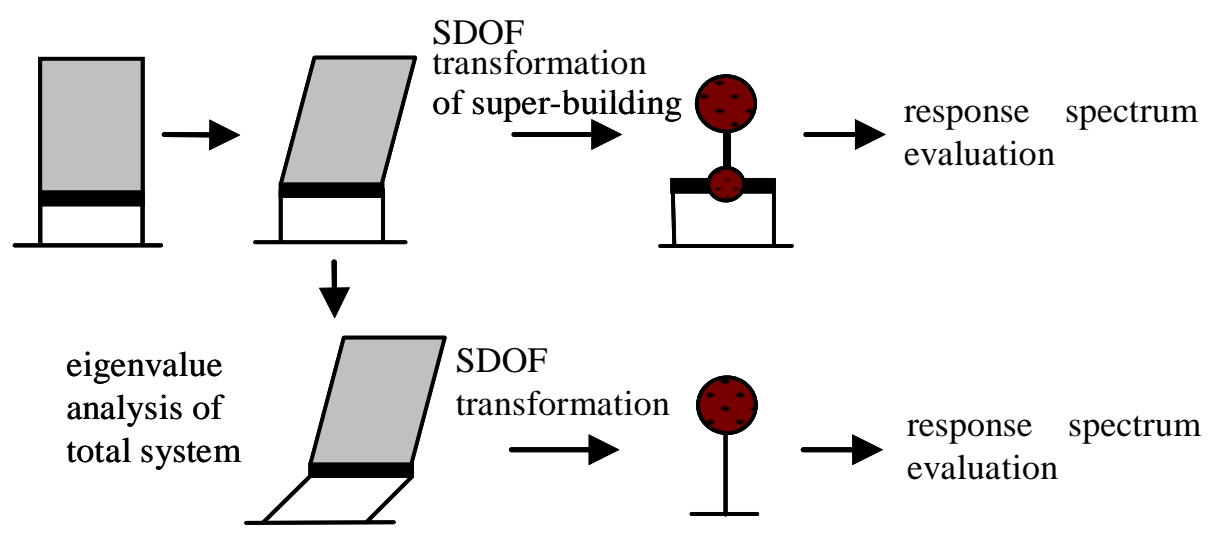

Fig.4 Schematic diagram of the procedure for evaluating the response base shear coefficient with respect to the aspect ratio in terms of SDOF and 2DOF models

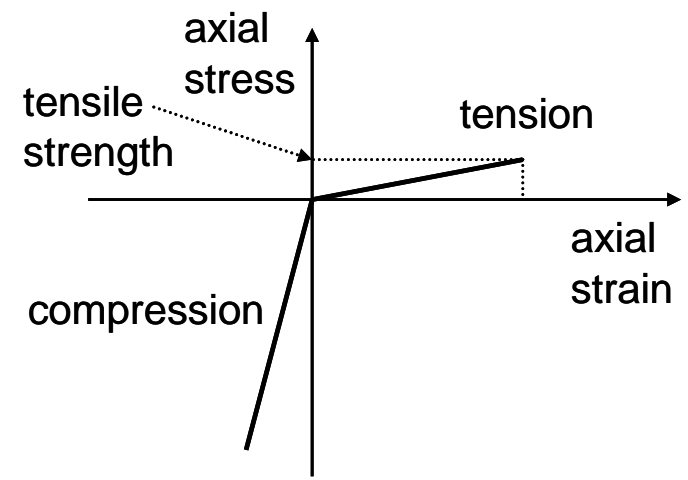

Fig.5 Nonlinear axial stress-strain relation of rubber bearing 


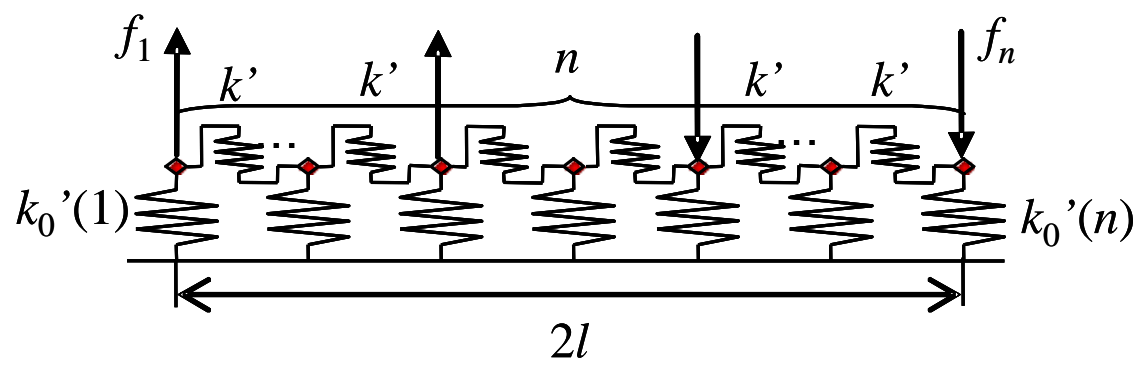

Fig.6 Simple model consisting of axial springs modeling rubber bearings and the shear springs modeling connecting beams

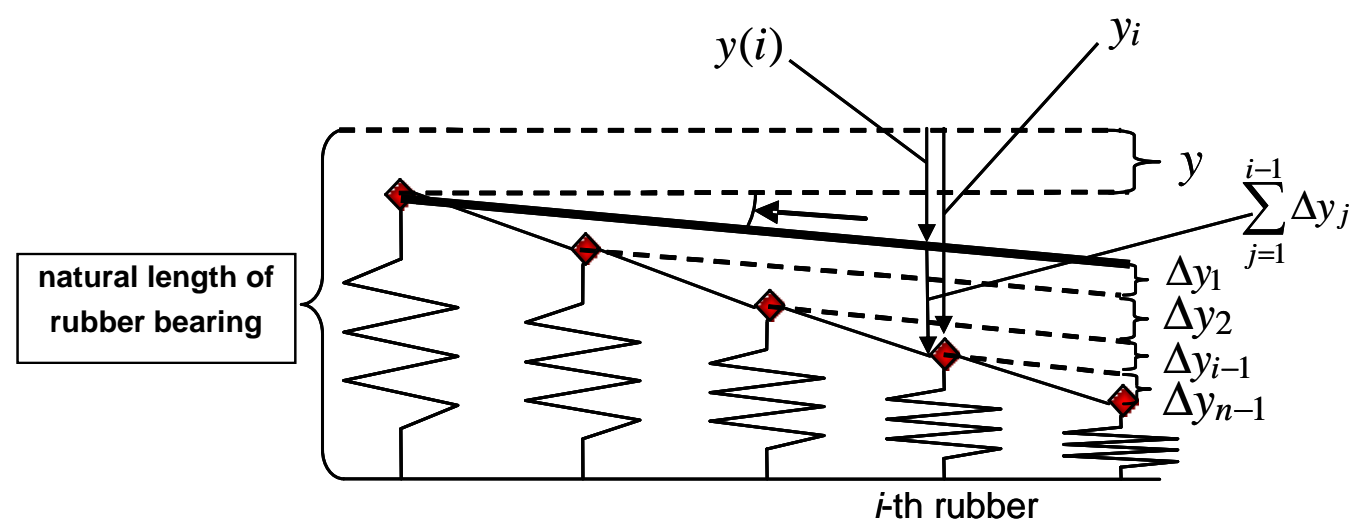

Fig.7 Definition of total axial deformation $y_{i}$ of the $i$-th rubber bearing consisting of the component $\sum_{i-1}^{i-1} \Delta y_{j}$ due to shear deformation of the connecting beam and that $y(i)=y_{i}-\sum_{j=1}^{i-1} \Delta y_{j}$ excluding the component of shear deformation of the connecting beam 


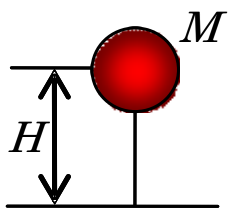

SDOF model

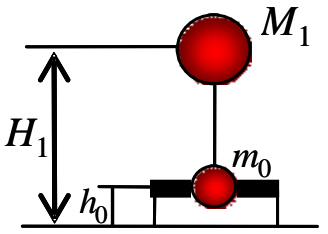

2DOF model consisting of SDOF super-structure and base-isolation system

Fig.8 Reduced SDOF model and 2DOF model for evaluation of response base shear coefficient and response overturning moment under seismic loading

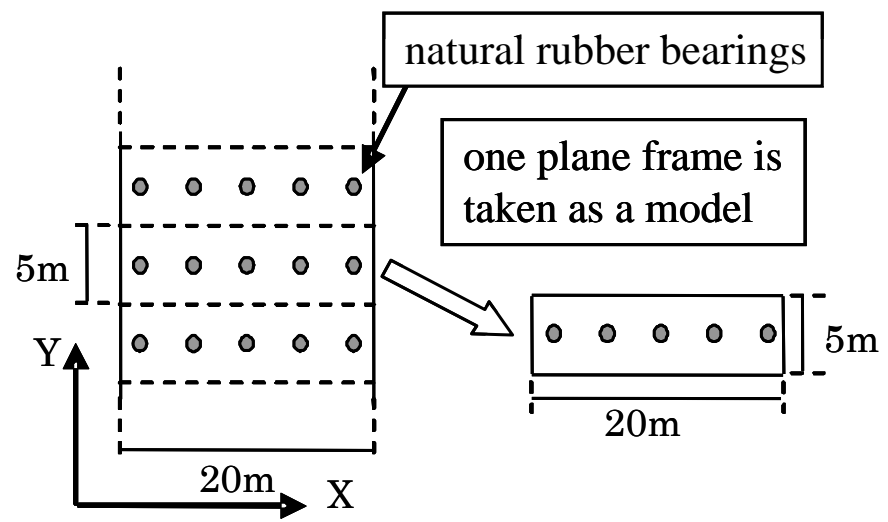

Fig.9 Plan of model building 

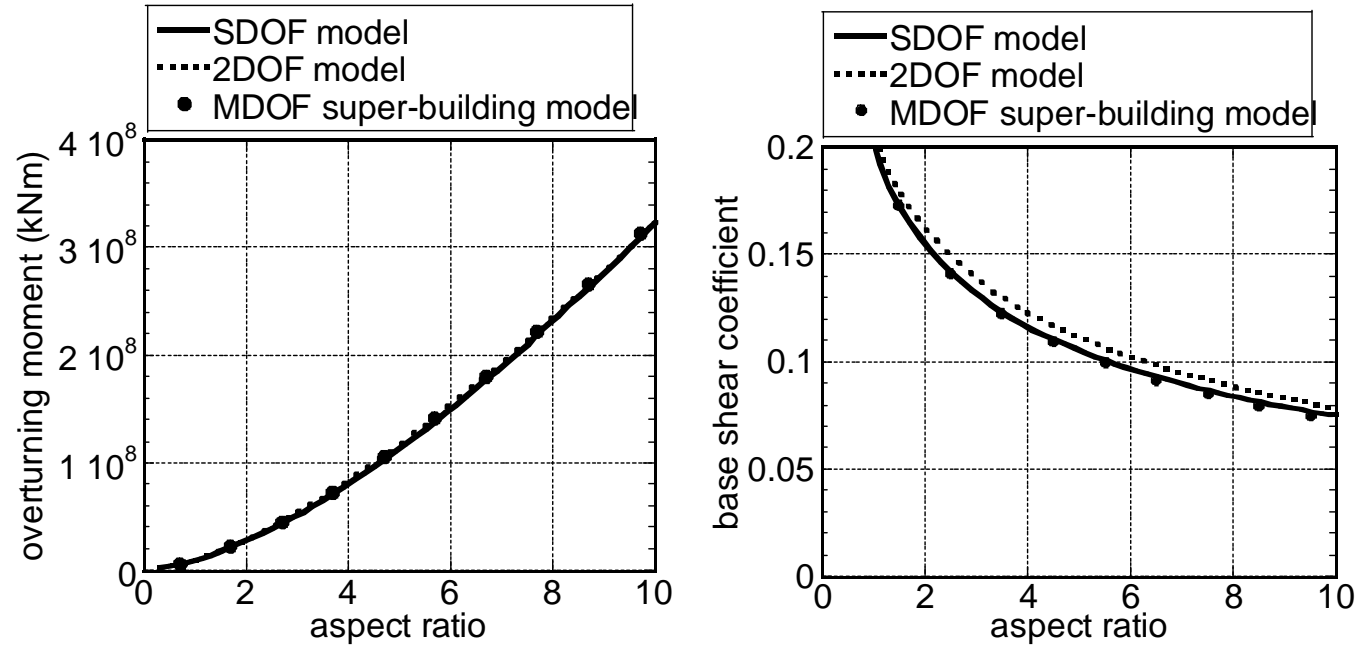

Fig.10 Response overturning moment at the base with respect to the aspect ratio and the response base shear coefficient with respect to the aspect ratio

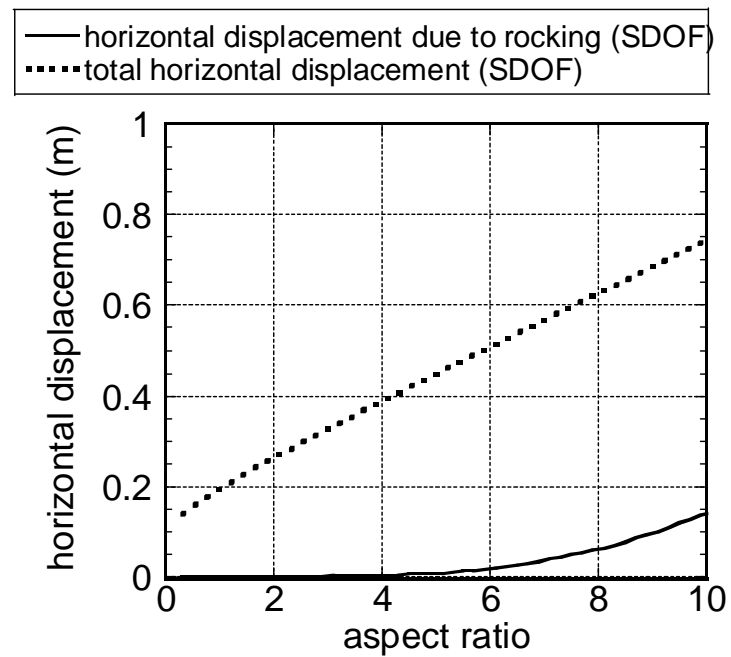

Fig.11 Comparison between the horizontal displacement of the SDOF model and the horizontal displacement at the same height level due to the rocking of the connecting beam 


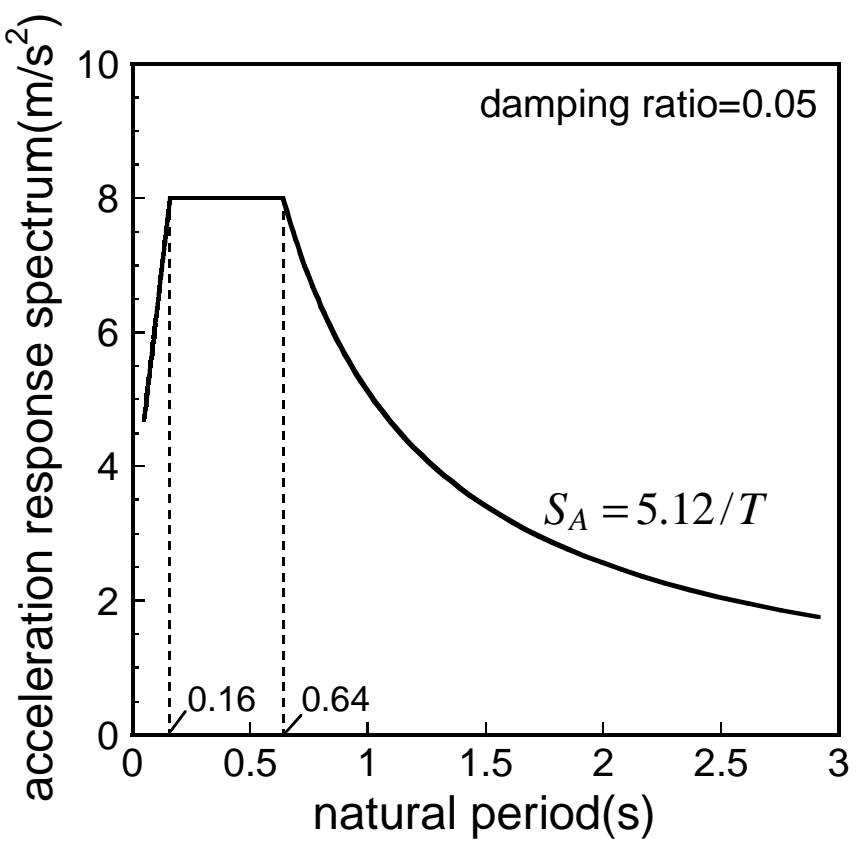

Fig.12 Acceleration response spectrum for large earthquakes used in Japan (2000) 


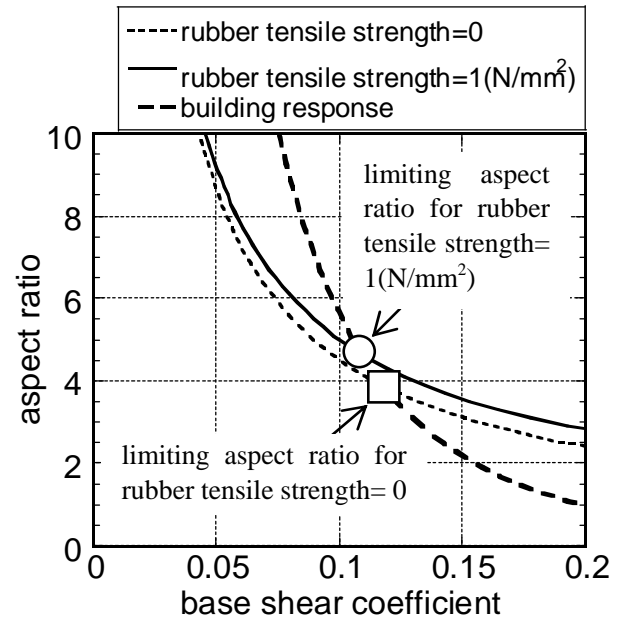

(a) beam stiffness: $1.95 \times 10^{6} \mathrm{~N} / \mathrm{m}$

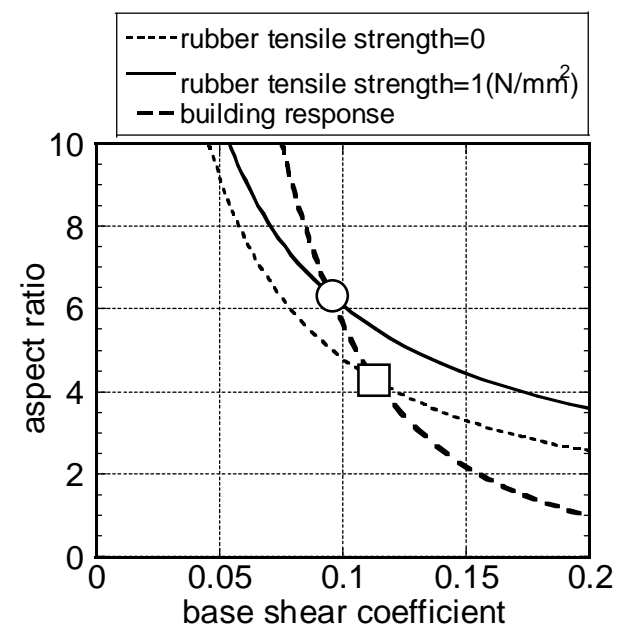

(c) beam stiffness: $1.95 \times 10^{9} \mathrm{~N} / \mathrm{m}$

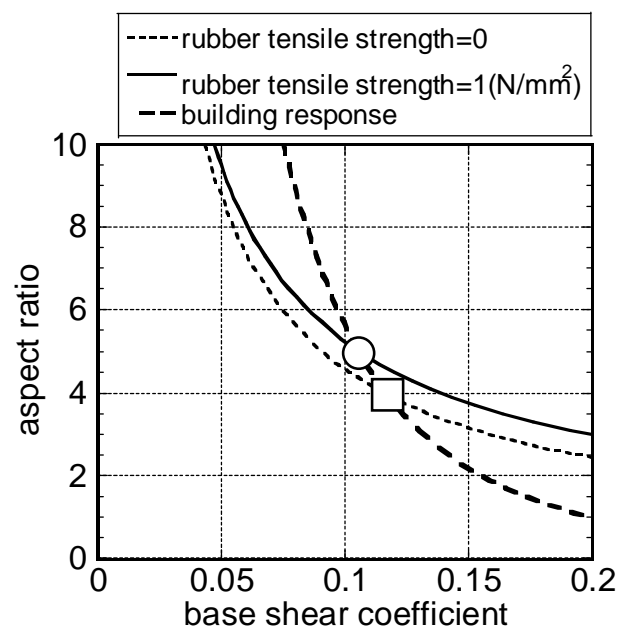

(b) beam stiffness: $1.95 \times 10^{8} \mathrm{~N} / \mathrm{m}$

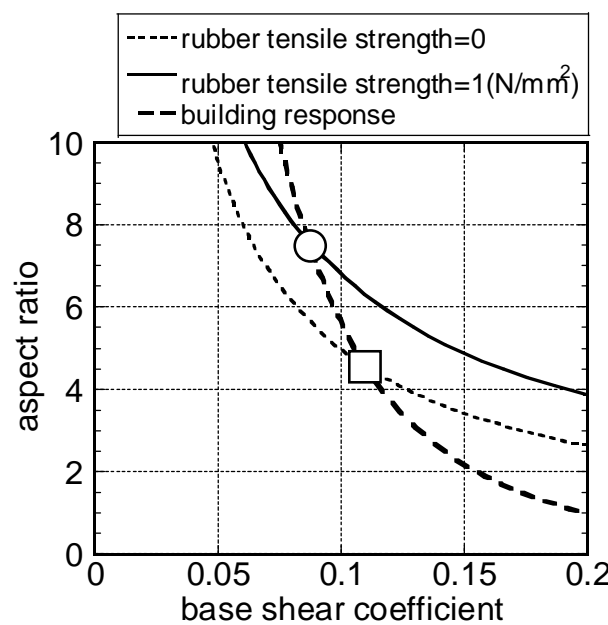

(d) beam stiffness: $1.95 \times 10^{11} \mathrm{~N} / \mathrm{m}$

Fig.13 Relation of the aspect ratio with the base shear coefficient in the case where the design condition on ultimate tensile state of rubber bearings is active (four cases of connecting beam shear stiffnesses $1.95 \times 10^{6} \mathrm{~N} / \mathrm{m}, 1.95 \times 10^{8} \mathrm{~N} / \mathrm{m}, 1.95 \times 10^{9} \mathrm{~N} / \mathrm{m}$, $\left.1.95 \times 10^{11} \mathrm{~N} / \mathrm{m}\right)$ 


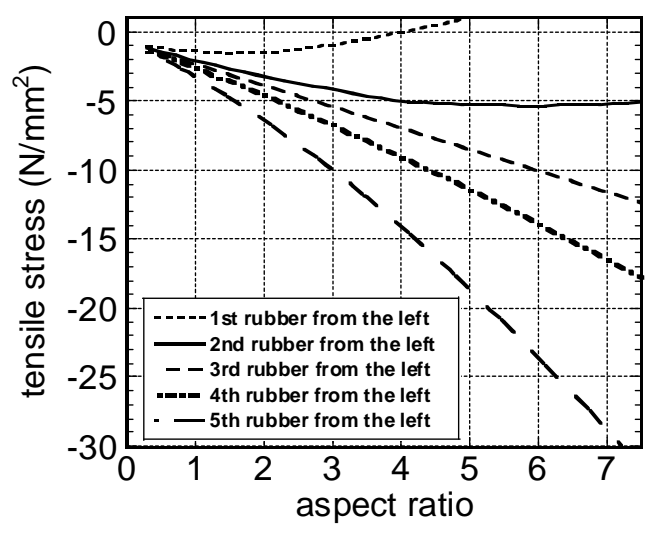

(a) beam stiffness: $1.95 \times 10^{8} \mathrm{~N} / \mathrm{m}$

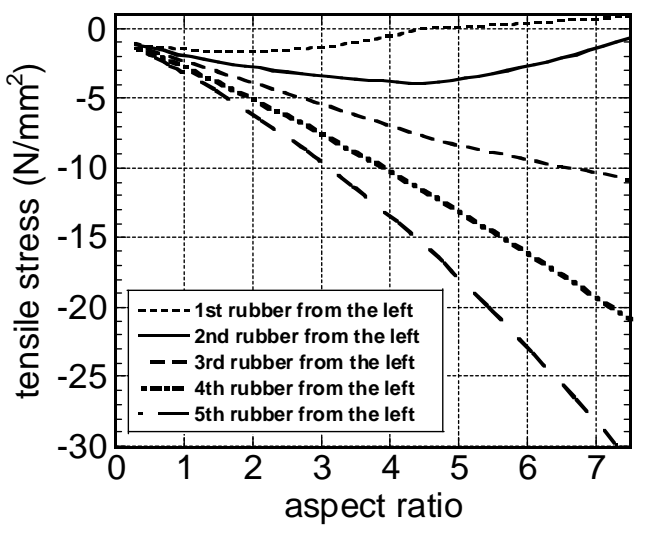

(b) beam stiffness: $1.95 \times 10^{11} \mathrm{~N} / \mathrm{m}$

Fig.14 Variation of axial stresses of five rubber bearings with respect to the aspect ratio for two different connecting beam stiffnesses

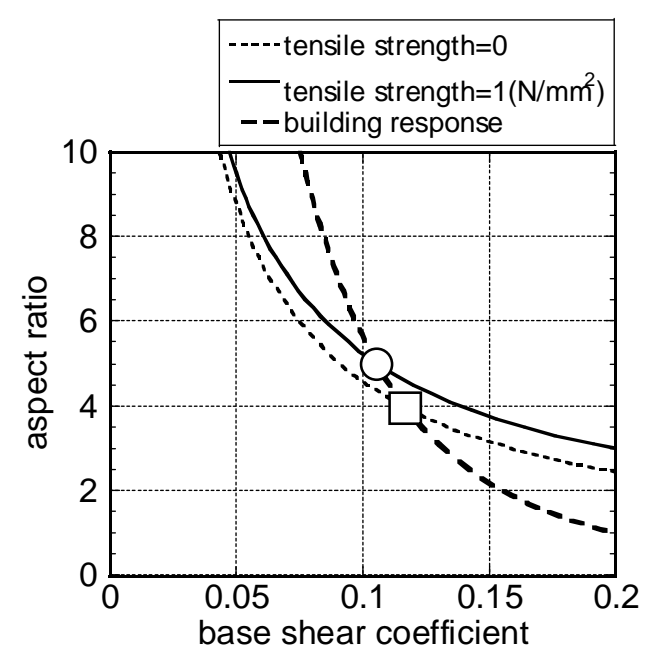

(a) without vertical input

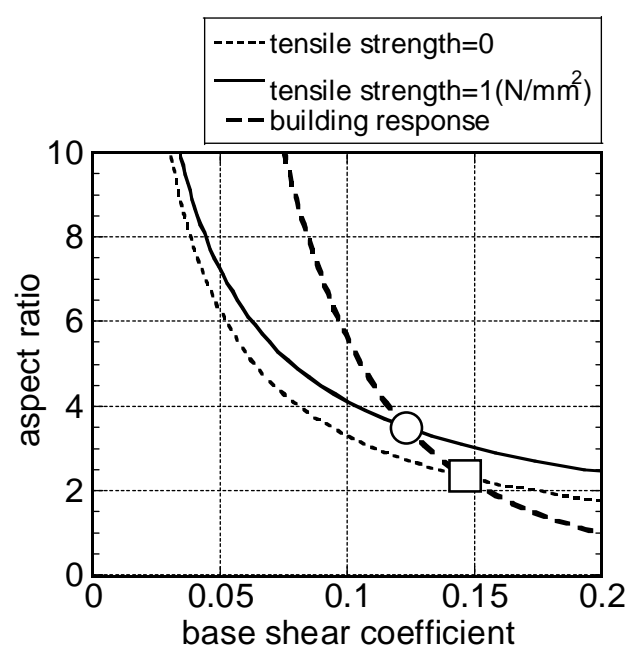

(b) with vertical input (0.3g)

Fig.15 Comparison of the limiting aspect ratio between the case without the consideration of the vertical seismic loading and that with the consideration of the vertical seismic loading 

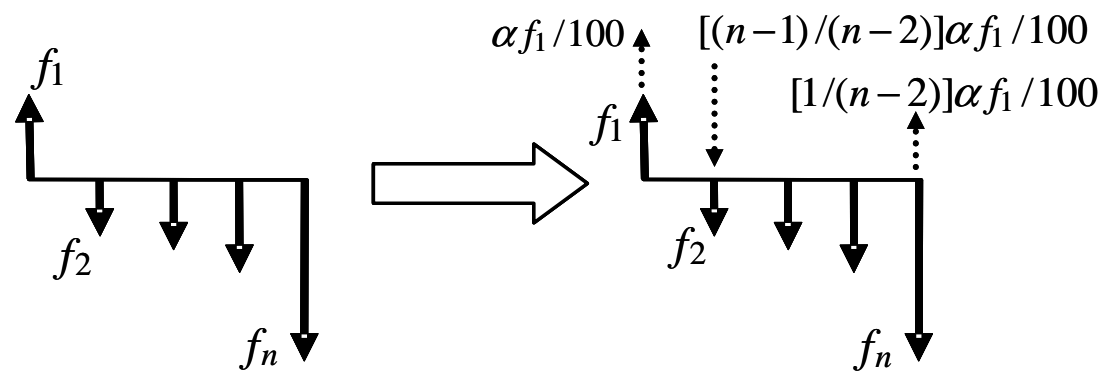

Fig.A1 A possible scenario of redistribution of column axial forces resulting from the nonlinear tensile behavior of the rubber bearing at the left end

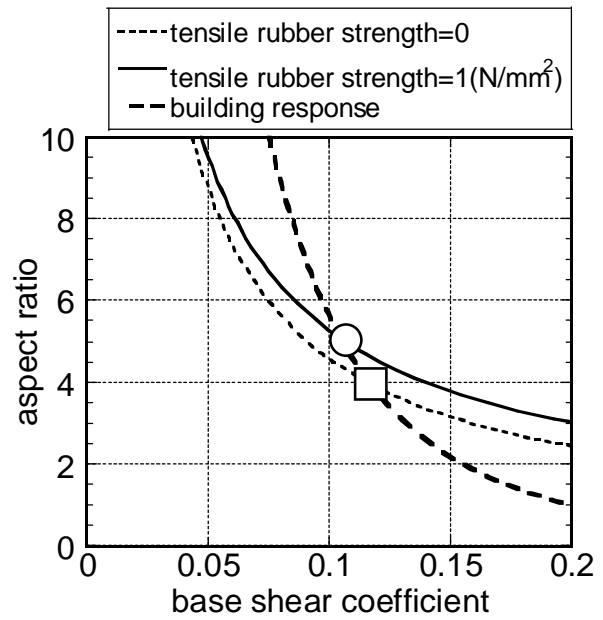

( a) $\alpha=0 \%$

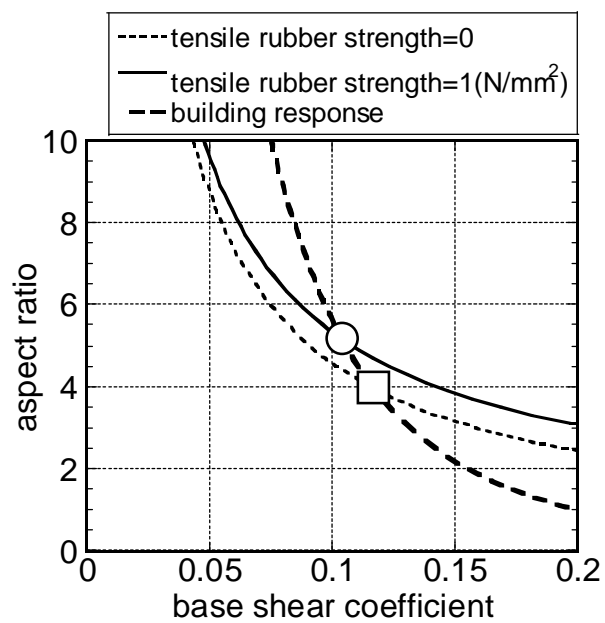

( c) $\alpha=-10 \%$

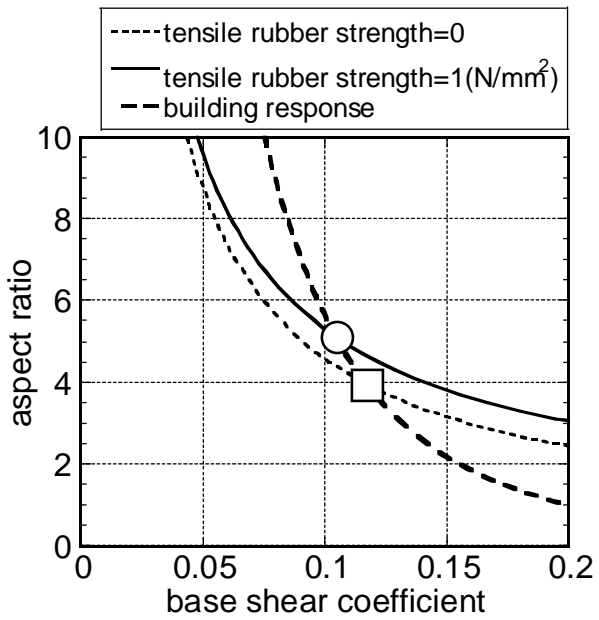

( b) $\alpha=-5 \%$

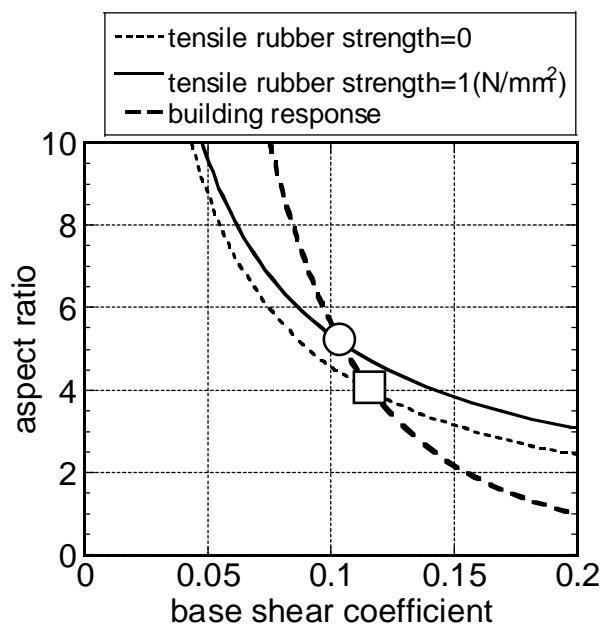

( d) $\alpha=-15 \%$

Fig.A2 Relation of the aspect ratio with the base shear coefficient for four redistribution cases of column axial forces 


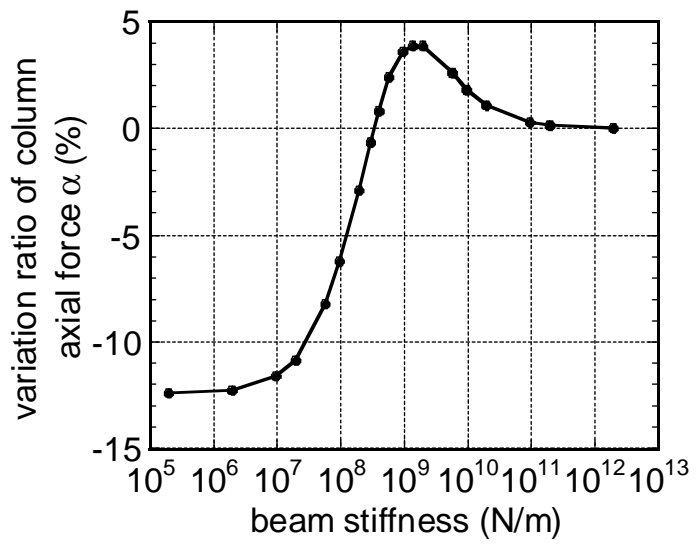

Fig.A3 Variation of the left-end column axial force under seismic loading with respect to the variation of the connecting beam stiffness 